\title{
NUMERICAL AND EXPERIMENTAL STUDY OF FAILURE IN STEEL BEAMS UNDER IMPACT CONDITIONS
}

\author{
E. D. Morales ${ }^{1}$, A. Y. Yoneda ${ }^{1}$, L. Driemeier ${ }^{1}$, R. Celeghini $^{1}$, M. Alves ${ }^{1}$ \\ ${ }^{1}$ Department of Mechatronics and Mechanical Systems Engineering, Polytechnic School at \\ the University of São Paulo (edumorales@usp.br)
}

\begin{abstract}
The Finite Element Method is a numerical analysis technique that has been extensively used in industry, and one specific area of development is the study of impact simulation and assessment of energy absorption capability of materials. However, the energy absorption capability is directly dependent on material ductility, so that in order to correctly predict the onset of failure it is necessary to have accurate failure criteria. The objective of this work is to study the applicability of different failure criteria available in commercial finite element codes, in the simulation of stainless steel beams under impact. Initially, material characterization was done through several experimental tests which involve tensile tests and Hopkinson Bar tests. Next, impact tests were made with clamped beams. A high speed camera was used to record the experiments, and electronic devices were built in order to synchronize experimental data with the high speed image acquisition system. All experimental tests were simulated by using Finite Element Method and simulation results were compared to the experimental ones in order to verify the accuracy of failure criteria employed.
\end{abstract}

Keywords: Impact, Failure Criteria, Numerical Simulation, Material Characterization.

\section{INTRODUCTION}

Study of failure in structural members under dynamic loading such as beams, plates and thin shells is of great importance in the assessment of safety and hazard in many engineering problems regarding industries like nuclear, offshore, naval and defense. These problems generally involve large inelastic deformations and damage, and different modes of failure can be attained for structural members, so that in this case beams have been studied extensively by scientists for the development of reliable methods allowing prediction of onset for different failure modes for these critical elements.

Menkes and Opat [8] conducted experimental studies regarding dynamic behavior and failure of clamped beams subjected to uniformly distributed impulsive loading and three general failure modes were identified: large inelastic deformation (Mode I), tensile tearing (Mode II) and transverse shear failure at supports (Mode III). Theoretical rigid-plastic analysis was developed by Jones [3] which showed good agreement with experimental results for prediction of failure modes II and III based on impact velocities. Further studies by Liu and Jones [7] showed that two modes of failure observed in Drop Hammer experiments - 
tensile tearing and shear failure, the last one not necessarily near supports - depend on type of material (mainly the rupture strain), position of impact point and clamping condition. Besides these failure modes, there are several studies on dynamic response of beams under impulsive loadings [1, $4-6,9]$.

The main objective of the present work is the study of applicability of the commonly used failure criteria in finite element simulations of impact phenomenon. The simulation of impact, in turn, is of great importance regarding the design of structures which are capable of absorb impact energy in an efficient and controlled way. However, in order to obtain reliable results from numerical simulations, it is necessary to calibrate material and failure models present in finite element software. To that end, experimental tests were made from which the desired parameters can be obtained. This work involves characterization of material considered as well as experimental tests and numerical simulations.

\section{METHODOLOGY}

Initially it is necessary to characterize the material, which is an AISI 304 stainless steel alloy available in $3 \mathrm{~mm}$ thick plates, so that quasi-static and dynamic experimental tests were made in tensile machine and Hopkinson Bar machine respectively, in order to find material parameters that can represent the behavior of material under low and high strain rates. The material model considered is the simplified form of Johnson-Cook material model [2], whose equation corresponds to Equation 1, and the simplified Johnson-Cook failure model corresponds to Equation 2.

$$
\begin{gathered}
\sigma=\left[A+B \varepsilon^{n}\right] \cdot\left[1+C \cdot \ln \left(\frac{\dot{\varepsilon}}{\dot{\varepsilon}_{0}}\right)\right] . \\
\varepsilon_{f}=D_{1}+D_{2} \cdot \exp \left(D_{3} \cdot \sigma^{*}\right) . \\
\sigma^{*}=\frac{\sigma_{h}}{\sigma} .
\end{gathered}
$$

In Equation $1 \sigma$ is the equivalent stress, $\varepsilon$ is the equivalent plastic strain, $\dot{\varepsilon}$ is the strain rate and $\dot{\varepsilon}_{0}$ is the reference strain rate. In Equation 1, parameters $A, B, n$ and $C$ are the material constants that need to be calibrated. In Equation 2, $\varepsilon_{f}$ is the equivalent failure strain and $D_{1}, D_{2}$ and $D_{3}$ are parameters of Johnson-Cook failure model. The parameter $\sigma^{*}$ is the stress triaxiality, which is the ratio between hydrostatic stress $\sigma_{h}$ and equivalent stress $\sigma$.

The simplified Johnson-Cook material model could be calibrated by execution of tensile tests and Hopkinson Bar tests. The experimental apparatus is shown in Figure 1. Tensile test machine is an Instron machine with $50 \mathrm{kN}$ of load capacity. 

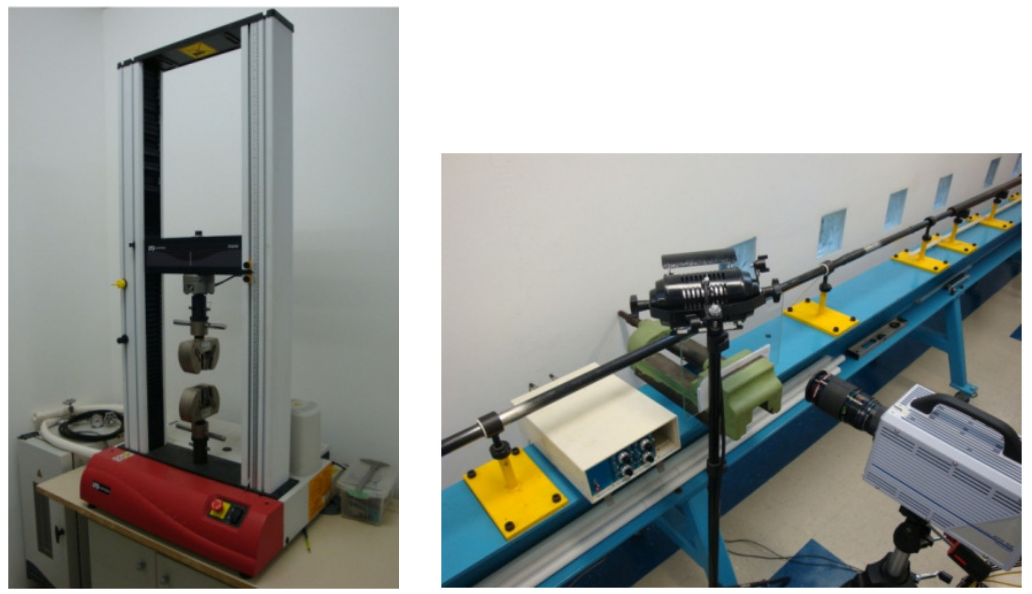

Figure 1. Instron tensile test machine (left) and Hopkinson Bar (right).

The Hopkinson bar test consists of two high strength steel bars, so that in the middle of which is placed the specimen, and one of bars (input bar) receives the impact of an impact bar (fired with compressed air). When impact of the impact bar occurs, a compression pulse propagates along input bar and reach the interface input bar - specimen. At that moment, part of pulse is transmitted to the specimen and part is reflected back to the input bar. The pulse transmitted, after finding the new interface specimen - output bar, suffers new reflection and partial transfer. In the input and output bars strain gauges are attached to measure the magnitude of deformation pulses and by using a formulation based on wave propagation it is possible to find the true stress-strain curve for specimen during the test.

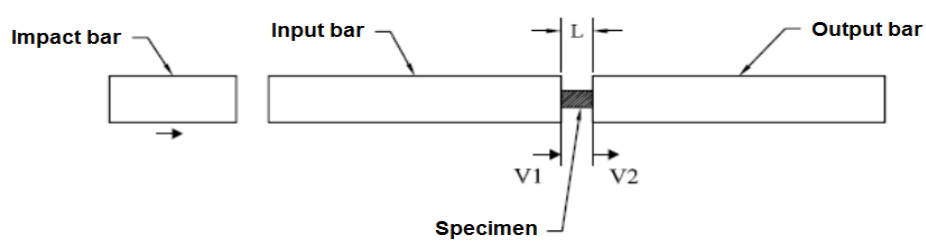

Figure 2. Schematic drawing of Hopkinson Bar machine.

\section{EXPERIMENTAL TESTS AND MATERIAL CHARACTERIZATION}

For the calibration of Johnson-Cook material model, were used unnotched dog-bone specimens for tensile tests and rings for Hopkinson Bar tests. Tensile tests with notched specimens also were made in order to obtain failure in different stress triaxialities, which can be used to do calibration of Johnson-Cook failure criterion. At least three tests with different stress triaxialities are required to generate data for curve fitting with Equation 2, so that besides standard dog-bone unnotched specimens, dog-bone specimens with $1.25 \mathrm{~mm}$ and $10 \mathrm{~mm}$ notch radius also were manufactured. Tensile tests specimens are $3 \mathrm{~mm}$ thick and have dimensions specified in Figures 3, 4 and 5. 


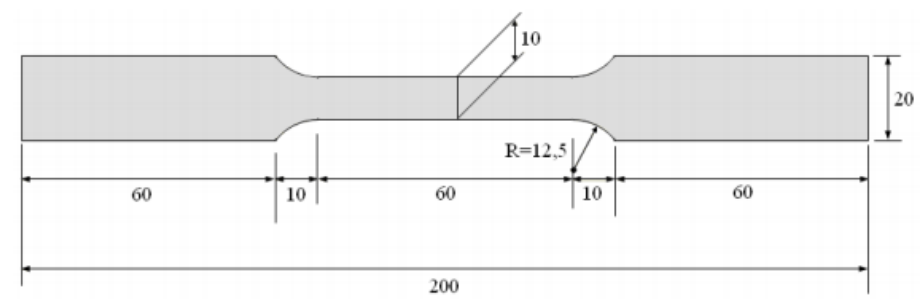

Figure 3. Unnotched dog bone specimen for tensile test.

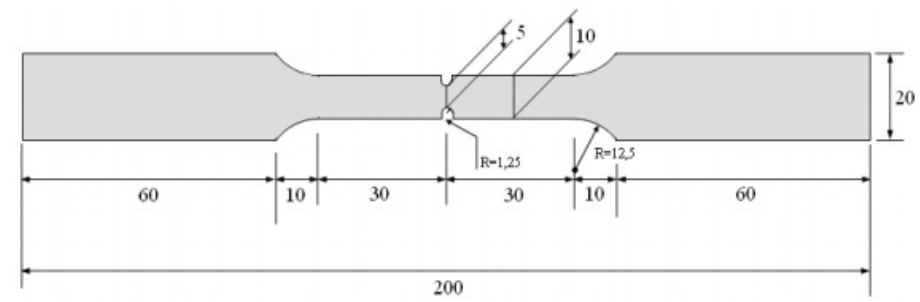

Figure 4. Notched dog bone specimen with $1,25 \mathrm{~mm}$ of notch radius.

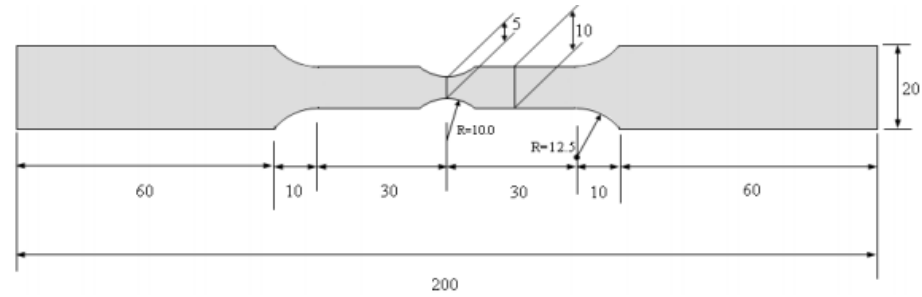

Figure 5. Notched dog bone specimen with $10 \mathrm{~mm}$ of notch radius.

The material considered is a high strength steel alloy, so that at the beginning of tensile tests loading and unloading cycles were made for tensile specimens in order to eliminate looseness in specimen attachments. This can avoid errors in results data that can affect parameters obtained such as elasticity modulus. Electronic clip gauges, which have gauge length of $\pm 25 \mathrm{~mm}$, were attached to specimens according to Figure 6 . After loading and unloading cycles in elastic regime, the loading of specimen continues until failure. A velocity of $0.006 \mathrm{~mm} / \mathrm{s}$ was applied to upper cross-head which gives a quasi-static strain rate of $1.2 \cdot 10^{-4} \mathrm{~s}^{-1}$.

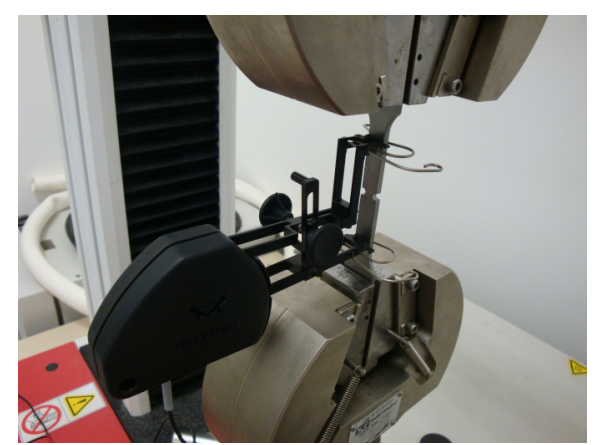

Figure 6. Electronic clip gauge attached to specimen.

Results for tensile tests are shown in Figure 7. A big difference is found for rupture strain when unnotched and notched specimen results are compared. 


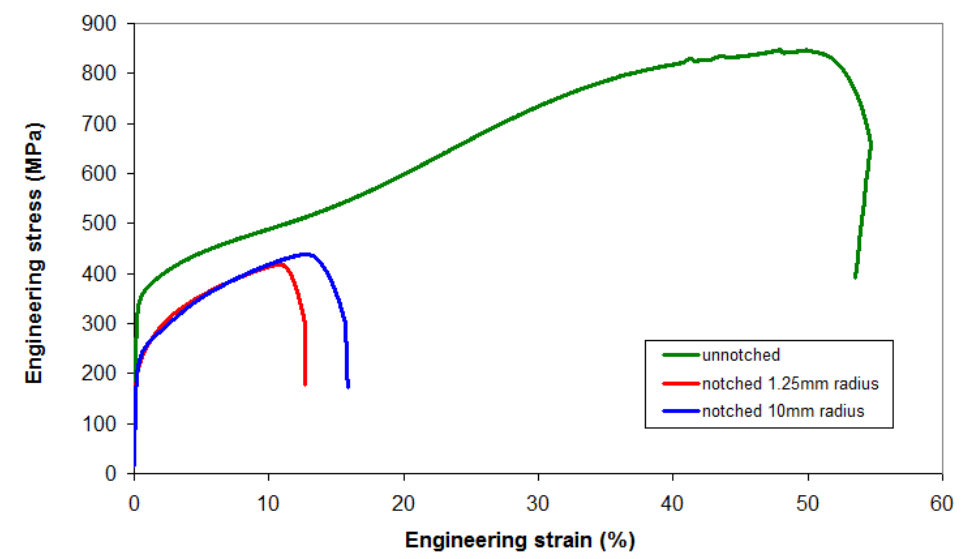

Figure 7. Results for tensile tests.

For Hopkinson bar test, rings $3 \mathrm{~mm}$ thick, with $20 \mathrm{~mm}$ of outer diameter and $17 \mathrm{~mm}$ of inner diameter were machined and tested at high strain rates up to $2000 \mathrm{~s}^{-1}$. The top strain rate used in this study $\left(2000 s^{-1}\right)$ was obtained by application of 4 bar of air pressure in pressure vessel to fire the impact bar. Lubrication of specimen was not applied, because unequal friction interaction can develop in different regions of specimen if lubrication is lost in some regions, so that an unequal radial expansion of specimen can occur. The fact of Hopkinson bar specimens be manufactured in shape of ring avoids greatly the requirement of lubricant, and because the thickness of rings is small, barreling effect occurring during compression was negligible. One Hopkinson Bar test was chosen for calibration of Johnson-Cook material model, and result is shown in Figure 8.

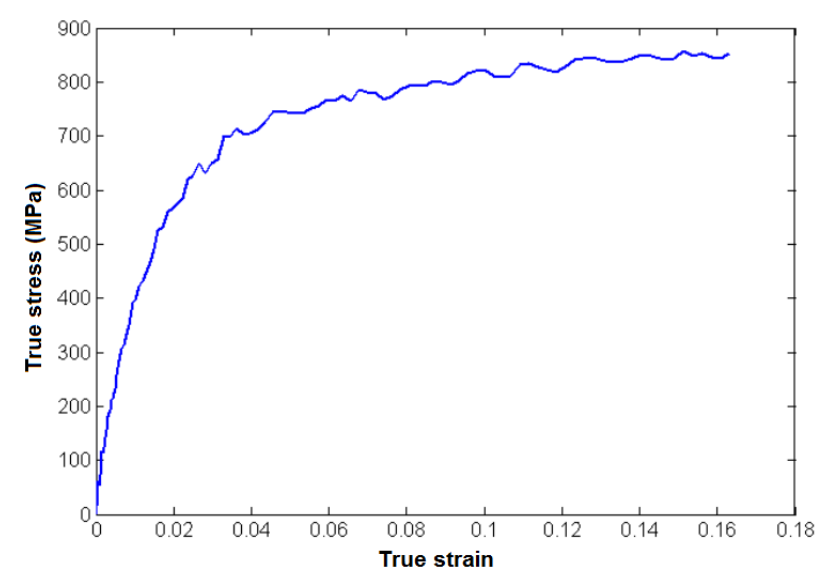

Figure 8. Results for Hopkinson bar test at highest strain rate $\left(2000 s^{-1}\right)$.

The experimental tests allowed the calibration of Jonhson-Cook material model, so that a set of parameters was obtained, which is shown in Table 1. All curve fitting procedures were done by using Matlab Curve Fitting Tool.

Table 1. Set of Johnson-Cook parameters.

\begin{tabular}{ccccc}
\hline $\mathrm{A}(\mathrm{MPa})$ & $\mathrm{B}(\mathrm{MPa})$ & $\mathrm{n}$ & $\mathrm{C}$ & $\dot{\varepsilon}_{0}\left(s^{-1}\right)$ \\
\hline 372.13 & 2200 & 0.999 & 0.0322 & $1.138 \cdot 10^{-4}$
\end{tabular}




\section{DATA SINCHRONIZATION SYSTEM}

In Impact Laboratory, a high speed camera recorder and a laser doppler velocimeter are available for utilization in experimental tests. However, to obtain more accurate data that could be used in numerical simulations, an electric circuit was built in order to synchronize the data acquisition system of Hopkinson Bar extensometers and the laser Doppler velocimeter with the high speed camera recorder. Synchronization is of great importance in these tests because for the case of camera, the definition of precise moment to start recording as well as the duration allows higher acquisition rates in recording (to obtain more frames per second). The built electric circuit is very versatile, because it uses an extra $12 \mathrm{~V}$ output power from camera recorder.
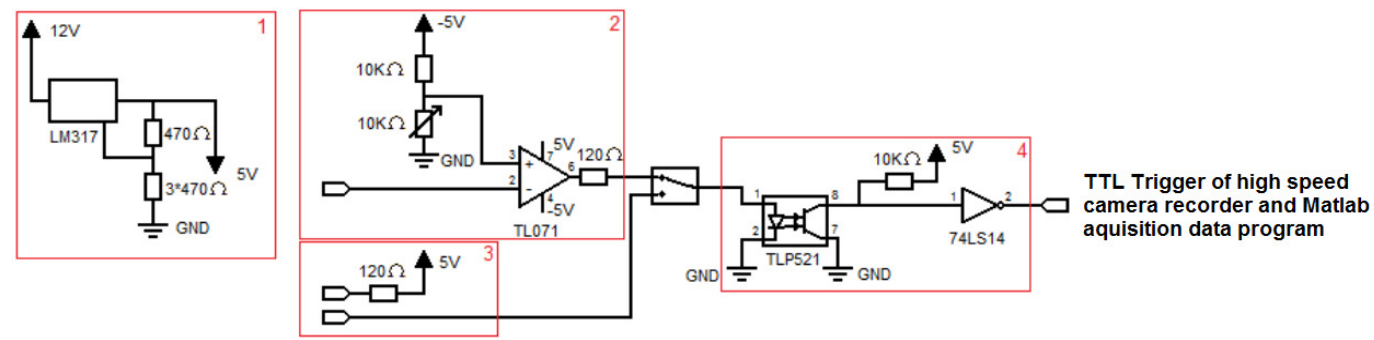

Figure 9. Diagram of data synchronization circuit.

The general diagram of synchronization circuit is outlined in Figure 9. It is composed of 4 major blocks numbered in Figured 9 and explained here. The block number one is an electric tension divider, which gives an output of $5 \mathrm{~V}$ by dividing the output electric tension of $12 \mathrm{~V}$ provided by high speed camera recorder. Block number two compares the electric signal of Hopkinson machine Input bar extensometer with a predefined level of tension in order to actuate the start of camera recording and data acquisition system. Block number three is the circuit attached to striker in Drop Hammer tests for actuation of synchronization circuit; it consists of a simple circuit with a photodiode, which emits infrared light that is detected by a phototransistor of block four circuit. When striker pass through the phototransistor sensor, the emitted light by photodiode is detected and the synchronization circuit is activated. And finally, the block four circuit receives the photodiode signal from striker circuit or Hopkinson bar extensometer signal and outputs trigger signals for activation of camera recording and data acquisition system. It should be noted that phototransistor sensor is placed at the end of a cable and inside a cone shape protection in order to avoid other light interferences.

The circuit as it was built in electric board is shown in Figure 10. 


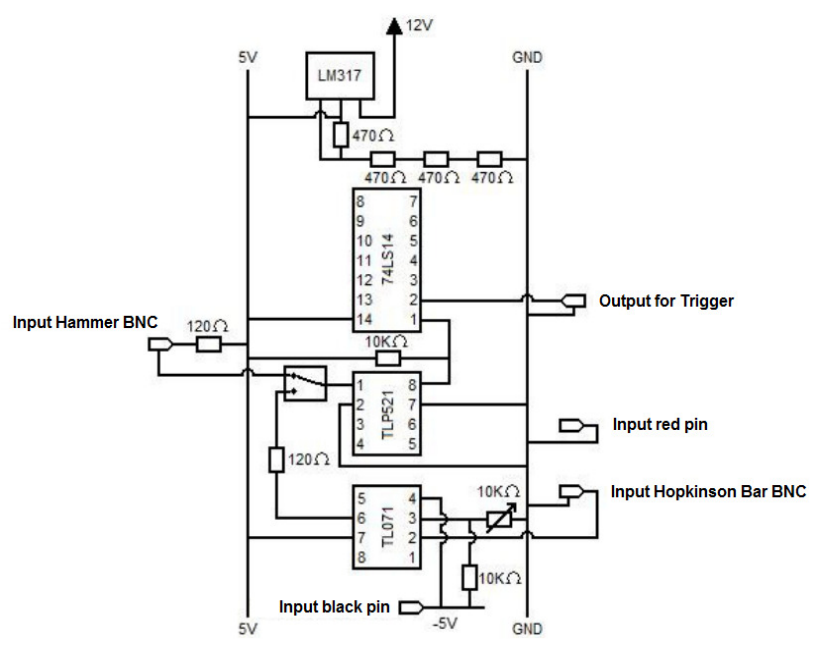

Figure 10. Data synchronization circuit.

Cable with phototransistor sensor and the small circuit that is coupled to striker of Drop Hammer are shown in Figure 11.

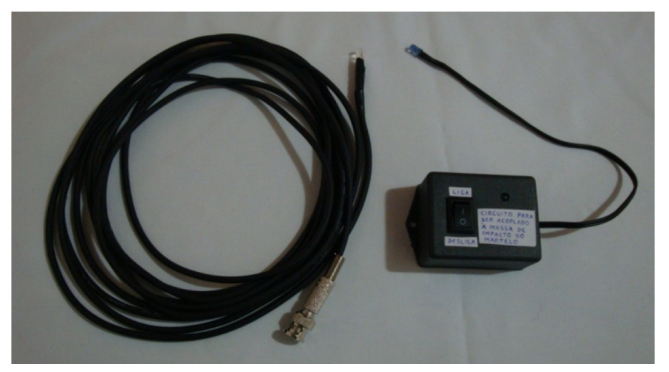

Figure 11. Cable with phototransistor sensor (left) and photodiode circuit that was attached to striker (right).

The main synchronization circuit outlined in Figure 10 is shown in Figure 12, and it can be seen the cable that is connected to high speed camera $12 \mathrm{~V}$ power output, as well as the outputs for triggering the camera and data acquisition system.

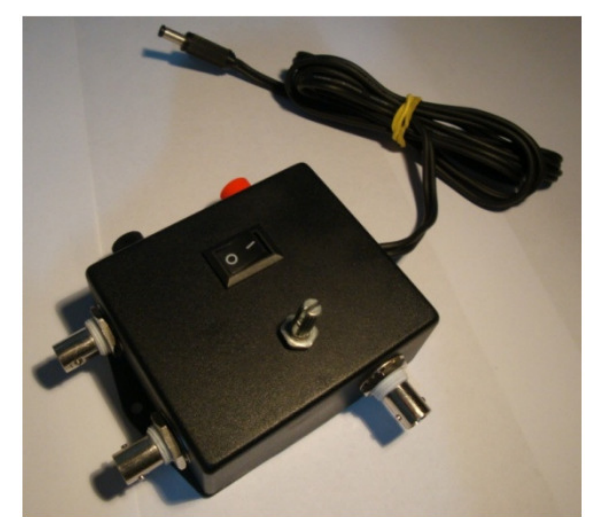

Figure 12. Main synchronization circuit.

The circuit attached to Drop Hammer striker is outlined in Figure 13 and shown in Figure 14. 


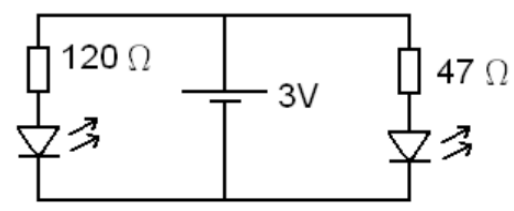

Figure 13. Diagram of circuit attached to striker.

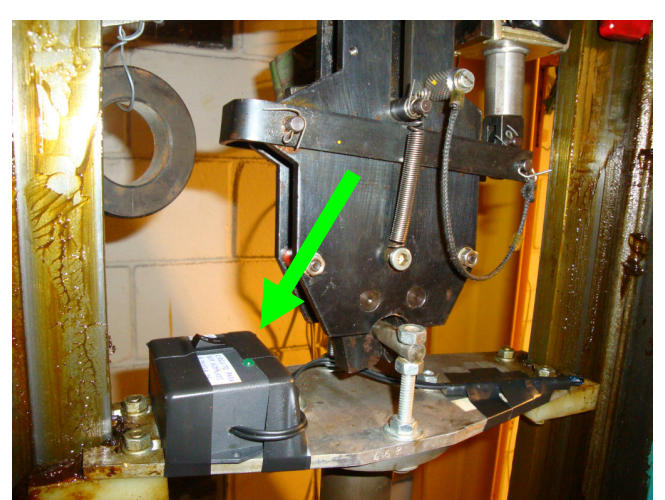

Figure 14. Circuit with photodiode attached to Drop Hammer striker

\section{NUMERICAL SIMULATIONS OF CHARACTERIZATION TESTS}

Numerical simulations of experimental tests for material characterization were performed with finite element solver LS-Dyna, in order to verify the accuracy of JohnsonCook parameter set obtained previously.

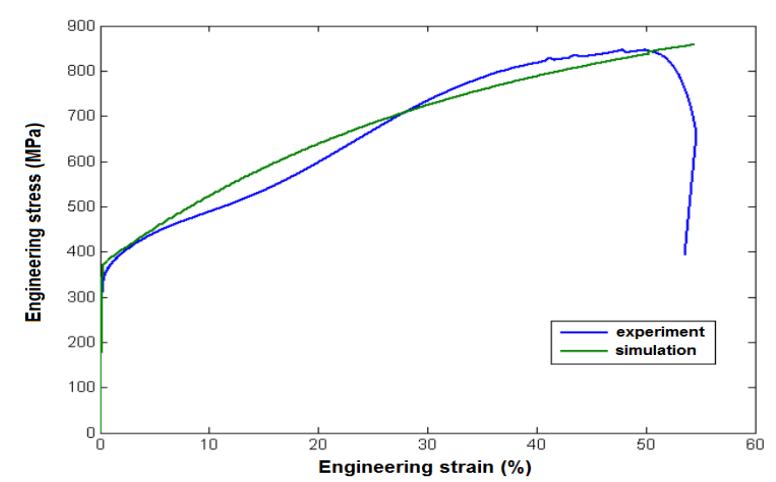

Figure 15. Results for unnotched tensile test simulation.

For simulation of tensile tests a hexahedral solid mesh was used, and for Hopkinson Bar tests a mesh of axisymmetric shell elements was employed, as shown in Figure 16. For tensile tests only a quarter of specimens were modeled, and appropriate boundary conditions were applied. Notched tensile tests were simulated in order to calibrate parameters for Johnson-Cook failure model. 


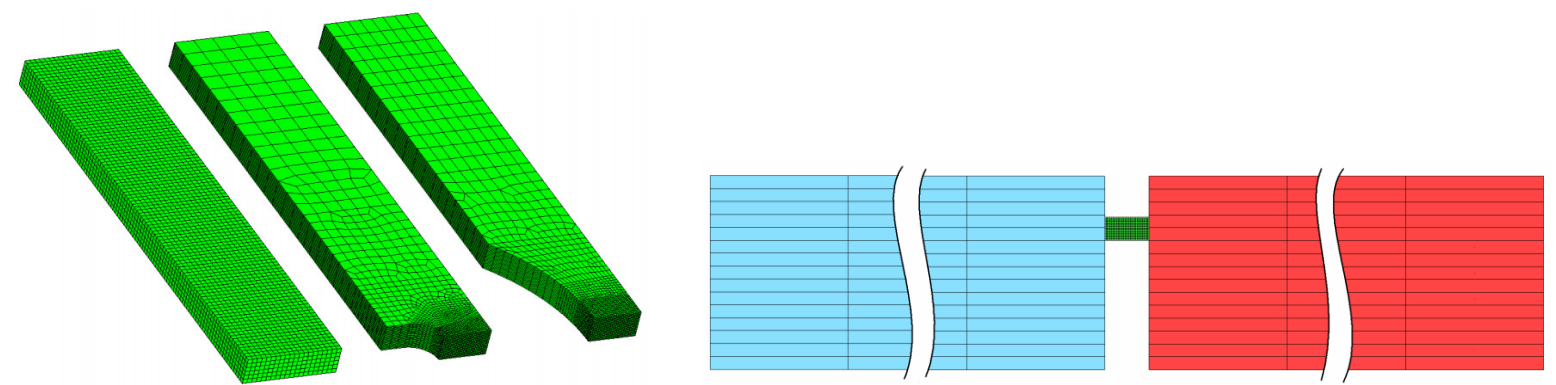

Figure 16. Solid meshes used for tensile test simulations (left) and axisymmetric shell mesh used for Hopkinson Bar test simulations (right).

In simulation of Hopkinson Bar tests, the modeling of impact bar collision was done through application of a compression pulse at the beginning of input bar, which is calculated based on filtered strain signal measured by input bar extensometer.

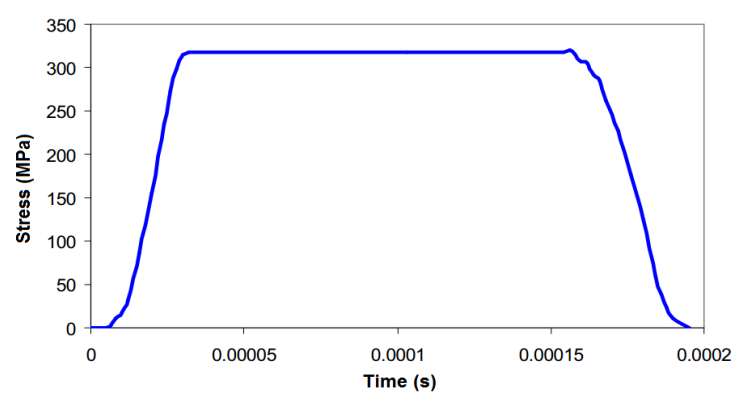

Figure 17. Compression pulse curve applied in input bar (4 bar test).

Results for simulations of Hopkinson Bar tests are listed in Table 2.

Table 2. Results for Hopkinson Bar test simulations.

\begin{tabular}{ccc}
\hline & External diameter $(\mathrm{mm})$ & Thickness $(\mathrm{mm})$ \\
\hline Test $1-2$ bar & 20.2 & 2.83 \\
Simulation - test 1 & 20.188 & 2.819 \\
Test 2 - 2 bar & 20.23 & 2.84 \\
Simulation - test 2 & 20.21 & 2.795 \\
Test 3 - 4 bar & 20.55 & 2.49 \\
Simulation - test 3 & 20.51 & 2.51
\end{tabular}

\section{EXPERIMENTS WITH DROP HAMMER}

Experiments were performed with steel beams in Drop Hammer. Specimens used are beams of $200 \mathrm{~mm}$ length, $6 \mathrm{~mm}$ wide and $3 \mathrm{~mm}$ thick, and were clamped in supports as shown in Figure 18. Beams were impacted at mid-span with 2 different types of indenters, and the length of beams between supports after clamping is $102 \mathrm{~mm}$. 


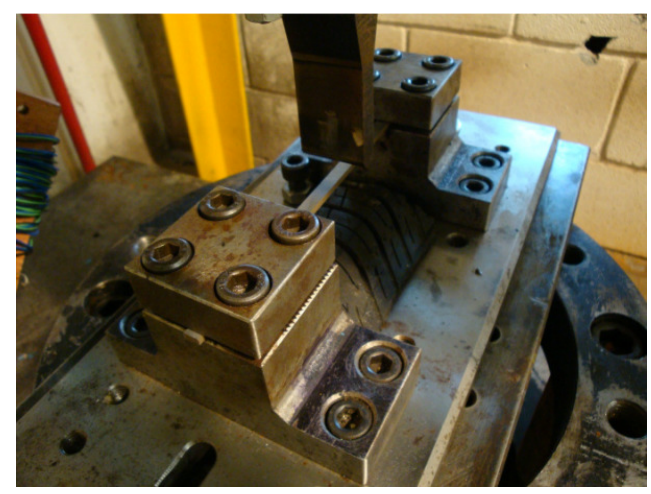

Figure 18. Beam specimen ready for test in Drop Hammer.

A laser Doppler velocimeter was used and positioned at a certain height above the specimen, as shown in Figure 19. It generates an output electric tension proportional to velocity measured, which is analyzed further in data acquisition system, so that a specific adjustment is done to velocimeter in order to obtain the highest accuracy possible in velocity range measured in tests.

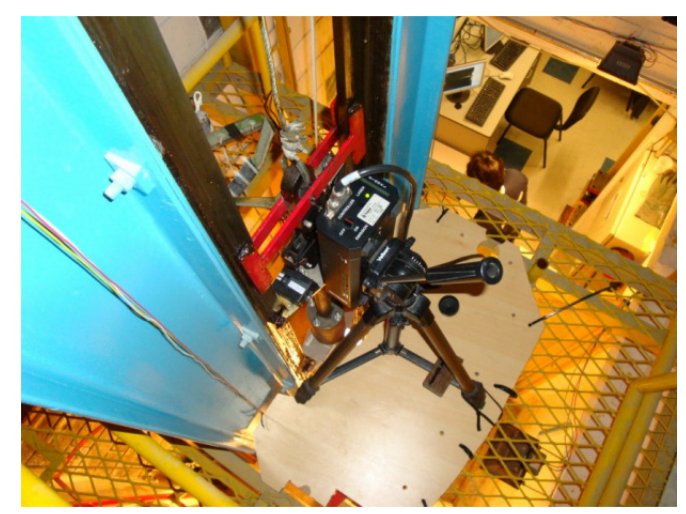

Figure 19. Laser Doppler velocimeter positioned in Drop Hammer.

For preliminary tests two indenters were tested: one with cylindrical shape and another one with rectangular shape. The cylindrical indenter generated failure in a region next to one of supports, whilst the region of contact between this indenter and beam was loaded in a tensile mode. Therefore, the rectangular shape indenter was adopted in all following tests, because sharp corners of this indenter can induce failure by shear mechanism at the point of contact with specimen.
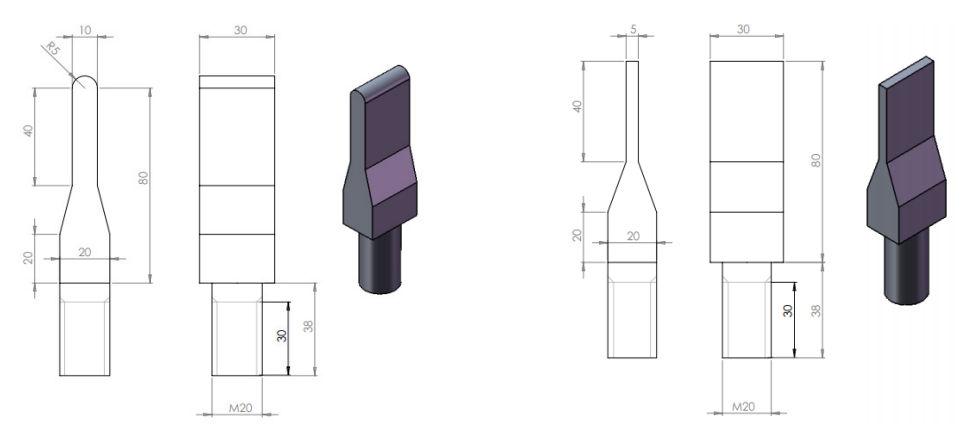

Figure 20. Two types of indenters tested in Drop Hammer. 


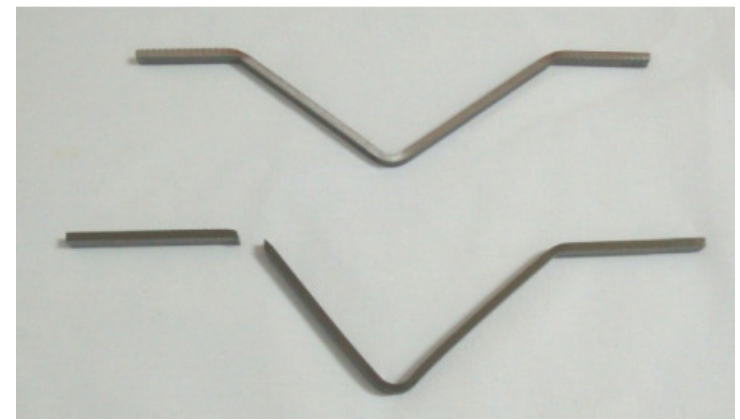

Figure 21. Results for two beams impacted with cylindrical shape indenter.

Drop Hammer tests were performed in two different days. In the first day, it was tested 4 beams with impact heights of $2.2 \mathrm{~m}, 2 \mathrm{~m}, 1.8 \mathrm{~m}$ and $1.6 \mathrm{~m}$. In the first three beams failure occurred, whilst in the last one failure was not verified. Tested beams appear in Figure 22.

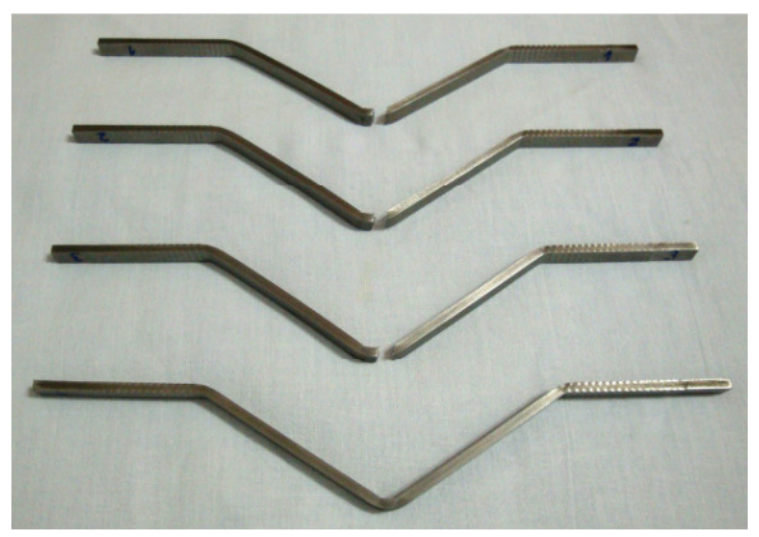

Figure 22. Four beams tested in the first day.

As no satisfactory results for velocity measurement with laser system were obtained for first 4 beams, it was executed new tests in a second day with new adjustments of equipment and better results could be obtained.

Tests were performed with 8 beams in the second day. In some tests bad measurements were obtained with laser Doppler velocimeter, however, most of tests presented satisfactory results. The vibrations in Drop Hammer structure as well as electromagnetic disturbances contributed for impossibility of obtaining velocity data in some experiments. Results obtained for experiments in second day are presented in Table 3.

Table 3. Results for experiments in second day.

\begin{tabular}{cccc}
\hline Beam & Impact velocity $(\mathrm{m} / \mathrm{s})$ & Impact height $(\mathrm{m})$ & Rupture \\
\hline 5 & 5.2975 & 1.79 & Yes \\
6 & Not obtained & 1.69 & No \\
7 & Not obtained & 1.69 & No \\
8 & 5.1736 & 1.69 & Yes \\
9 & Not obtained & 1.69 & Yes \\
10 & 5.0905 & 1.65 & Yes \\
11 & 5.0533 & 1.59 & Yes \\
12 & 4.7846 & 1.40 & No
\end{tabular}


It can be seen on Table 3 that 4 tests were performed in the height of $1.69 \mathrm{~m}$. This is due to the fact that at the beginning it was believed that this height would correspond to transition height for beams failure. However, since there was not repeatability in velocity data acquisition, this impact height was discarded.

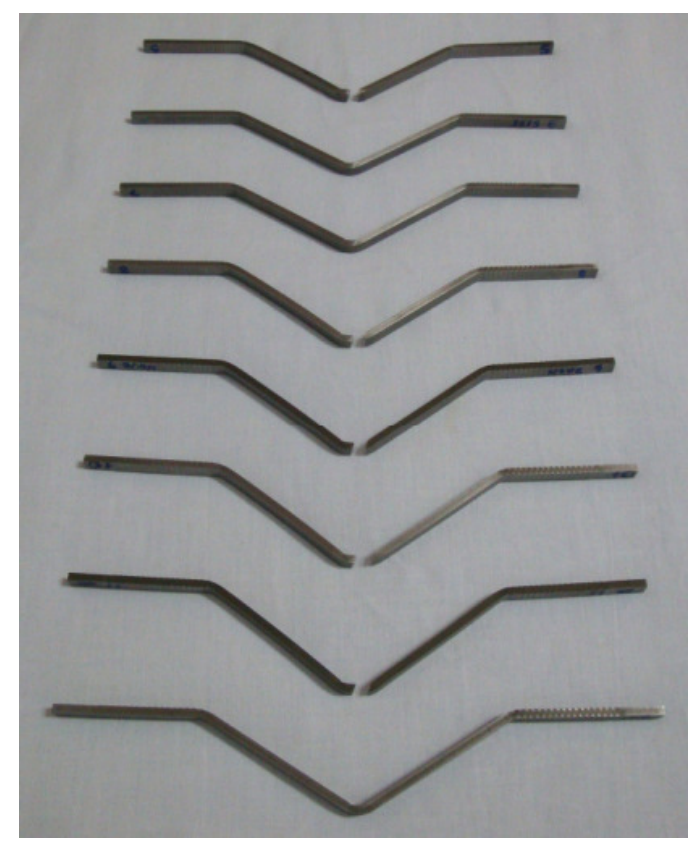

Figure 23. Eight beams tested in second day. The beam numbering is in increasing order ( 5 to 12) from top to bottom.

The failure of steel beams verified in tests occurred in a mixed mode: a small indentation on impact point can be seen in all tested beams, with and without failure. This indentation is caused by shear in a plane perpendicular to beam upper surface in impact region, as shown in Figure 24. Other failure mode is shear in a plane inclined 45 degrees from the beam axis, and this is caused by tensile stresses on the lower portion of beam in impact area.
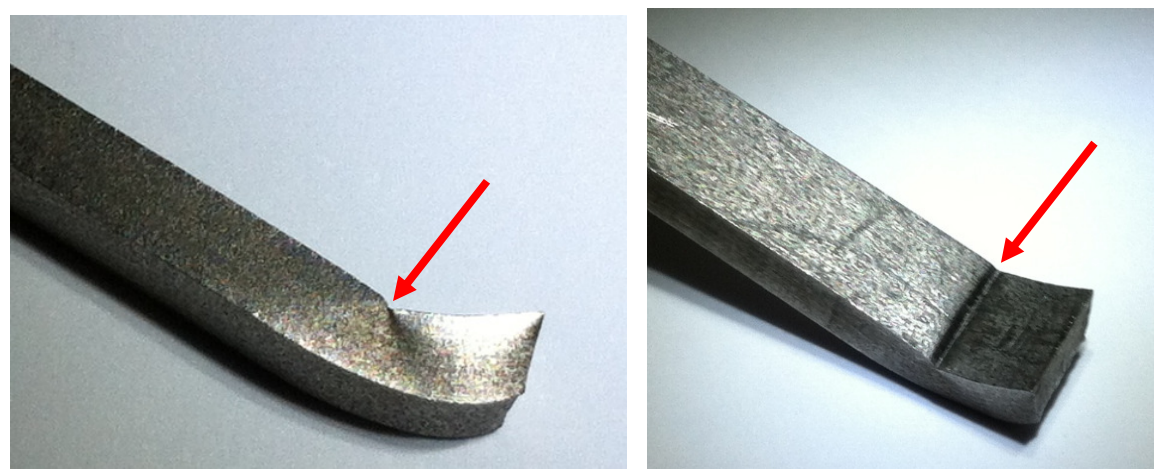

Figure 24. Indentation in a beam with failure. Indentation is caused by shear stresses induced by sharp edges of indenter, and it is verified in beams with and without failure.

In Figure 25, the failure surface has two different rugosities: one characteristic of failure by pure shear and another one characteristic of a failure by shear in a plane inclined 45 
degrees to loading direction, which can be seen in standard tensile tests. Therefore, a mixed mode failure in steel beams impacted at mid-span was verified here.

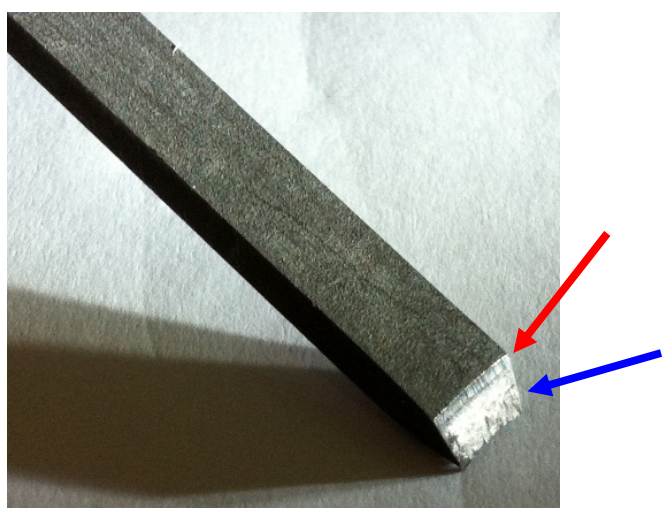

Figure 25. Failure surface of a steel beam impacted at mid-span. The red arrow points to smooth surface of indentation, caused by a state near pure shear. The blue arrow points to rugous surface characteristic of shear failure in a tensile state.

\section{CALIBRATION OF FAILURE CRITERIA}

For LS-Dyna, it were calibrated failure criteria based on maximum equivalent stress, maximum shear strain, maximum shear stress and maximum effective plastic strain. For calibration of each parameter it is considered the state of specimen in unnotched tensile tests when the maximum point of engineering stress-strain curve is reached. Results obtained for each parameter are listed in Table 4.

Table 4. Parameters for failure criteria.

\begin{tabular}{cc}
\hline Failure criterion & Value \\
\hline Maximum equivalent stress & $1251.327 \mathrm{MPa}$ \\
Maximum shear strain & 0.296 \\
Maximum shear stress & $622 \mathrm{MPa}$ \\
Maximum effective plastic strain & 0.396
\end{tabular}

The calibration for Johnson-Cook failure criterion was also made, by using the state of tensile test specimens at the moment when failure occurs, measuring plastic strain and stress state through simulation. The unnotched and notched specimens generated stress states of different triaxialities as shown in Table 5.

Table 5. Stress triaxialities and failure plastic strains for tensile tests.

\begin{tabular}{ccc}
\hline Specimen & Stress triaxiality & Failure plastic strain \\
\hline Unnotched & 0.33 & 0.399 \\
$10 \mathrm{~mm}$ radius notch & 0.38 & 0.347 \\
$1.25 \mathrm{~mm}$ radius notch & 0.51 & 0.325
\end{tabular}


The values in Table 5 were fitted to Equation 2 in order to find failure parameters. The parameter set obtained through data fitting is shown in Table 6. Curve fitting is shown in Figure 26.

Table 6. Johnson-Cook failure parameter set.

\begin{tabular}{ccc}
\hline $\boldsymbol{D}_{1}$ & $\boldsymbol{D}_{2}$ & $\boldsymbol{D}_{3}$ \\
\hline 0.321 & 94.26 & -21.53
\end{tabular}

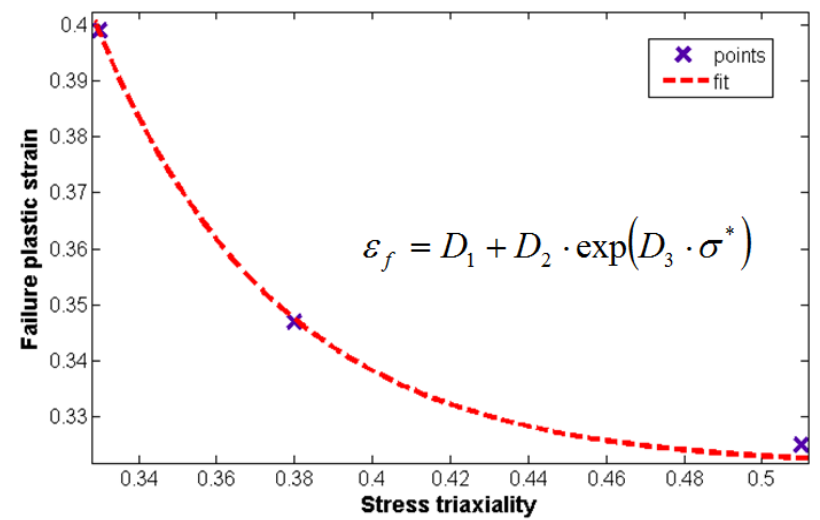

Figure 26. Curve fitting for Johnson-Cook failure criterion calibration.

\section{SIMULATIONS OF EXPERIMENTAL TESTS WITH DROP HAMMER}

For simulations of experimental tests with Drop Hammer, it was modeled one quarter of specimens, due to symmetry conditions, and 31104 hexahedral elements were used for each model with an average mesh size of $0.25 \mathrm{~mm}$. As boundary conditions, supports were modeled as rigid surfaces with friction of type "tied", the indenter as a rigid body with lumped mass and an initial velocity corresponding to measured velocity with laser Doppler velocimeter during experiment, before occurrence of impact.

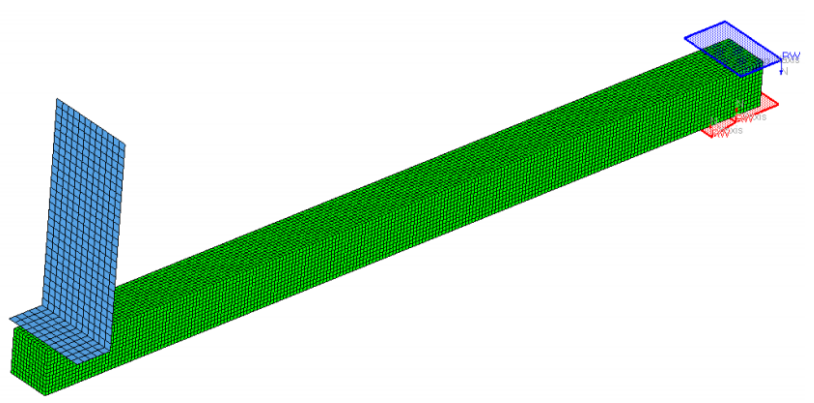

Figure 27. Finite element model of Drop Hammer experiment.

For simulation of Drop Hammer tests, tests with beam 10 (with failure) and 12 (without failure) were considered. 


\subsection{Simulations of test with beam 12 in Drop Hammer}

Test with beam 12 in Drop Hammer did not show failure and was simulated with LSDyna. Results obtained in simulation presented good correlation with experimental ones, according to Figure 28.
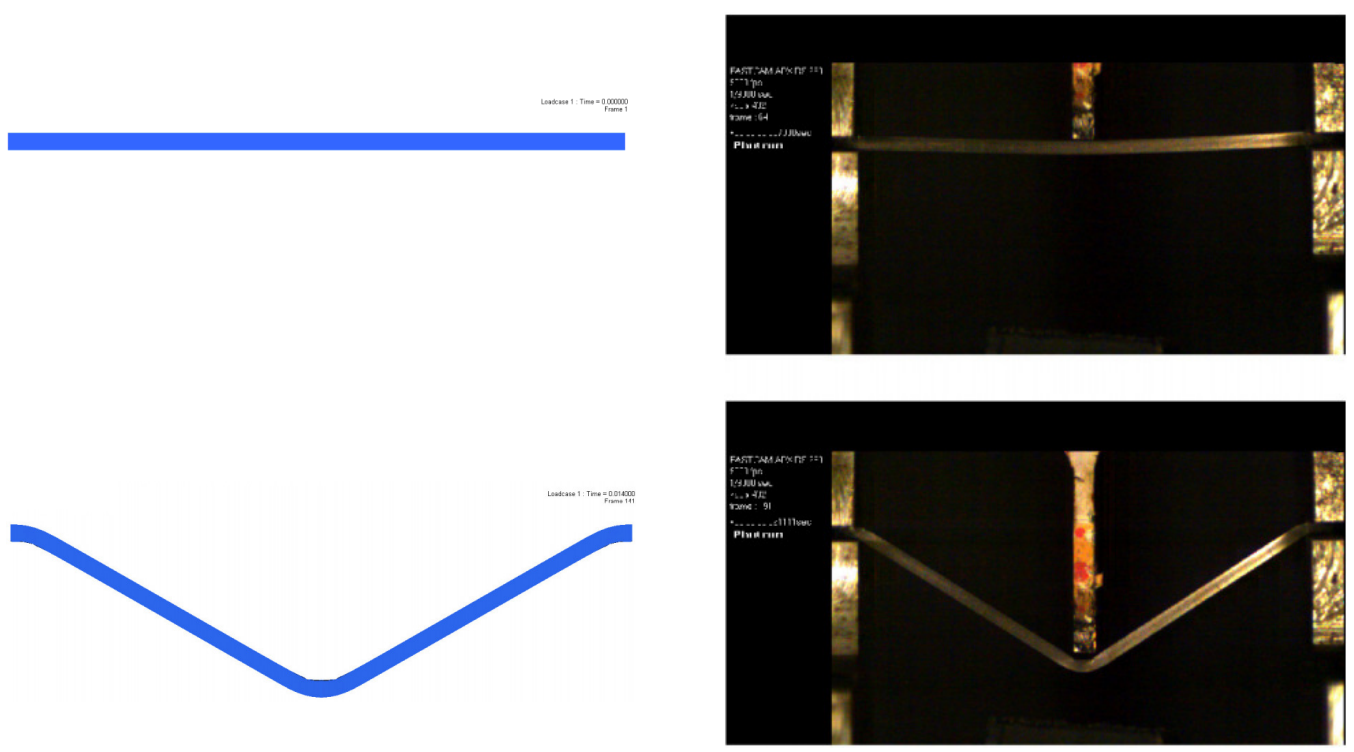

Figure 28. Simulation of Drop Hammer test with beam 12.

In simulation, the point of contact of beam 12 with indenter presented a vertical displacement of $26.6 \mathrm{~mm}$. In experimental test the displacement of same point was about $28.6 \mathrm{~mm}$.

\subsection{Simulations of test with beam 10 in Drop Hammer}

The criterion based on maximum shear strain was not able to generate failure during simulation. The maximum shear strain achieved during simulation is located at lower surface, and its value is 0.23 .

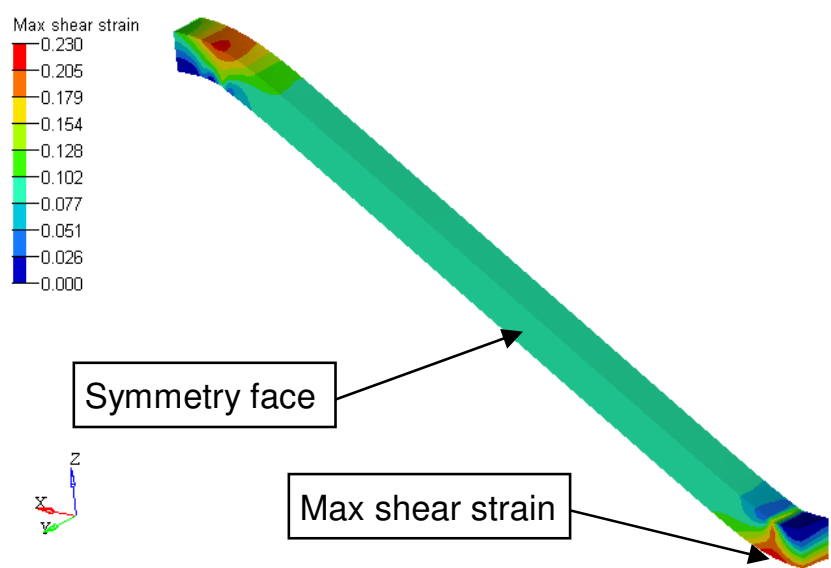

Figure 29. Distribution of shear strains after simulation. 
It can be seen from Figure 29 that maximum shear strains are achieved on lower surface under the impact point and on upper surface next to supports.

On the other hand, criterion based on maximum equivalent stress generated a failure in instant $0.0056 \mathrm{~s}$ after impact, whereas in reality failure occurs at instant $0.0076 \mathrm{~s}$.

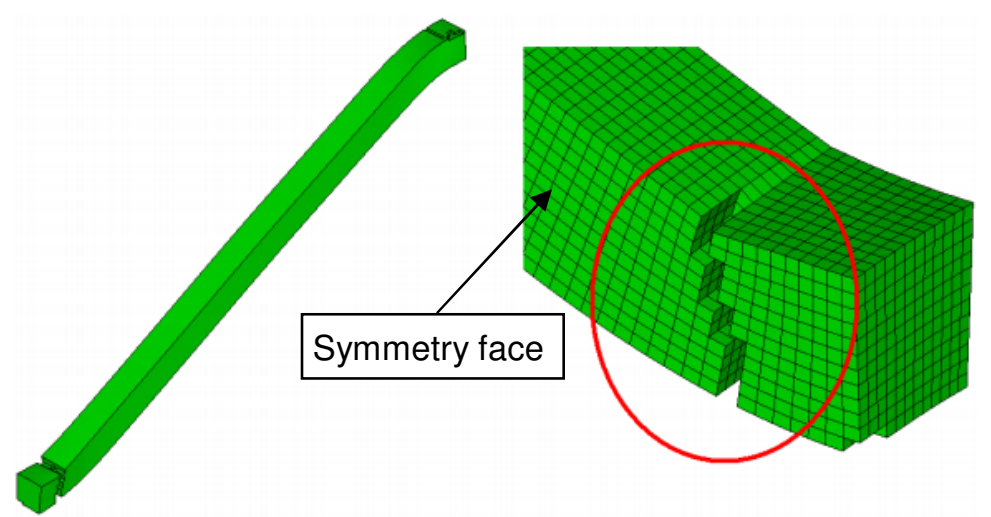

Figure 30. Simulation of Drop Hammer test with beam 10, using failure criterion based on maximum equivalent stress.

Plots of maximum equivalent stress distribution show that with maximum equivalent stress failure criterion the failure starts on the lower surface of specimen under the impact point, and propagates towards the upper surface.

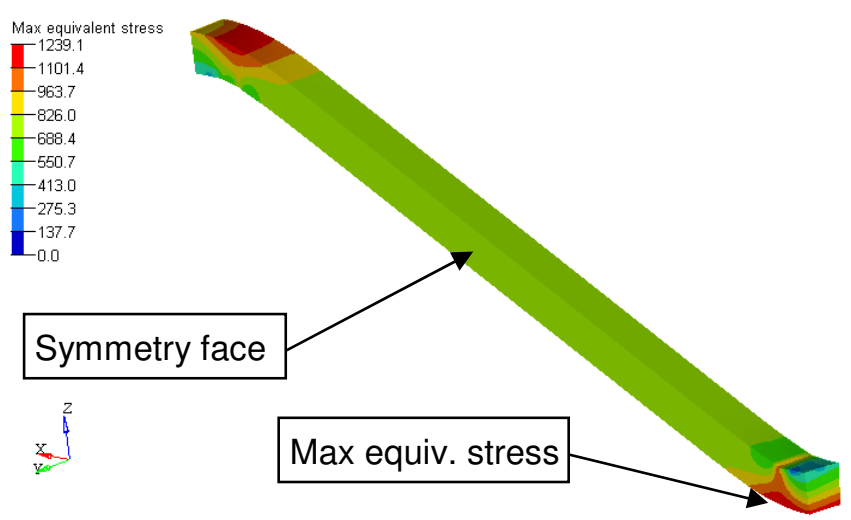

Figure 31. Simulation of beam 10, showing peak equivalent stresses on lower surface under impact point, before failure in simulation.

Failure criterion based on maximum shear stresses generated a premature failure at the instant $0.0045 \mathrm{~s}$ in simulation, whereas failure in reality occurs at $0.0076 \mathrm{~s}$. The resulting failure is shown in Figure 32. 

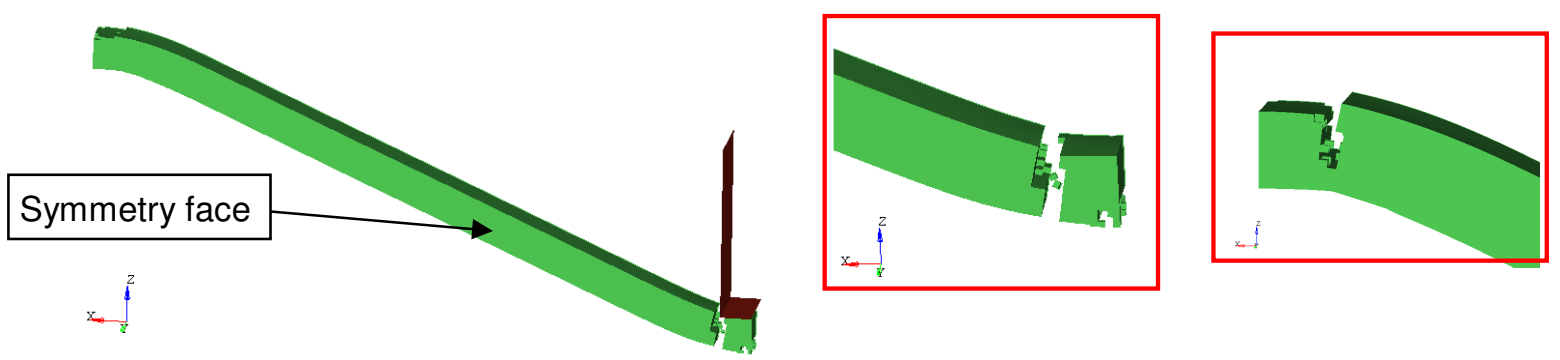

Figure 32. Simulation of beam 10 with maximum shear stress failure criterion. In center image, failure at contact region with support; in right image, failure next to support.

It is interesting to note that failure with max shear stress criterion also starts to occur next to supports after the failure in point of contact between indenter and specimen, so that almost an entire separation of material is seen in simulation, as illustrated in Figure 32.

Simulation with failure criterion based on maximum equivalent plastic strain did not generate failure, because critical effective plastic strain was not reached. But the maximum value of plastic strain was concentrated on an area in an opposite side from the symmetric face of specimen, which is a different result in comparison with other results.

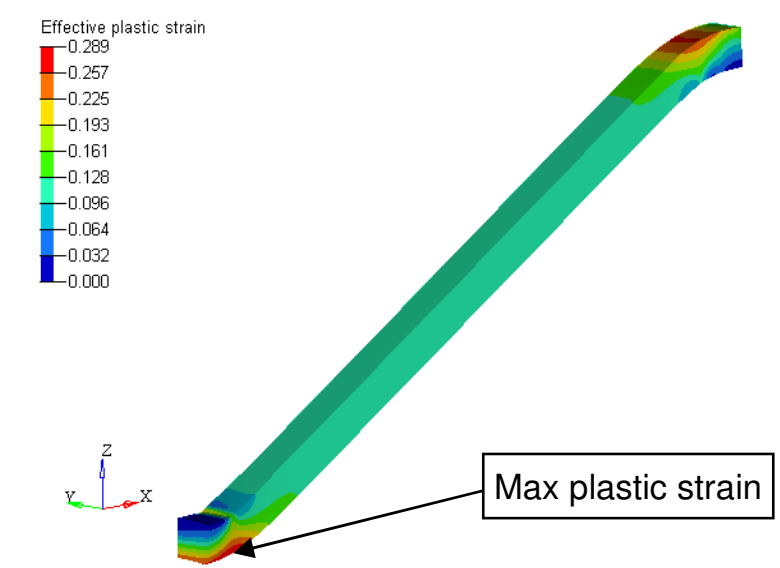

Figure 33. Simulation of beam 10 with maximum equivalent plastic strain failure criterion.

Simulation with Johnson-Cook failure criterion did not led to failure, although highest damage generated was concentrated on lower surface under impact point. Damage is calculated through Equation 4, as a sum of incremental damages obtained from ratio of incremental equivalent plastic strain and equivalent failure strain calculated for actual integration cycle. The actual equivalent failure strain varies with stress triaxiality according to Equation 2.

$$
D=\int \frac{d \varepsilon}{\varepsilon_{f}} .
$$

When damage variable $\mathrm{D}$ reaches unity for a given element, the element is removed from mesh. For present simulation the maximum damage reached with Johnson-Cook failure criterion is 0.83 , with a damage distribution shown in Figure 34. 


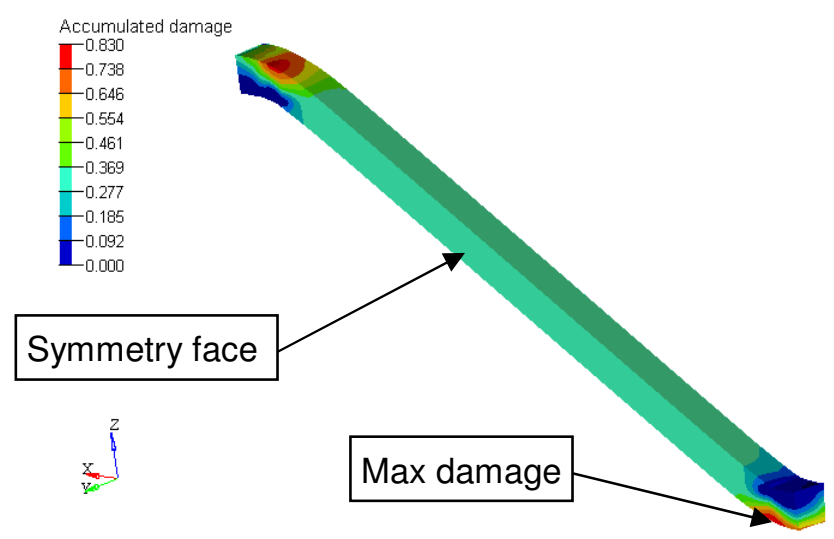

Figure 34. Simulation of beam 10 with Johnson-Cook failure criterion, with maximum damage reached on lower surface under impact point.

Mesh refinement was made in order to verify mesh sensitivity of results for failure criteria. A local refinement was made in impact region, with a reduction of mesh size by half. The mesh refinement is depicted in Figure 35.

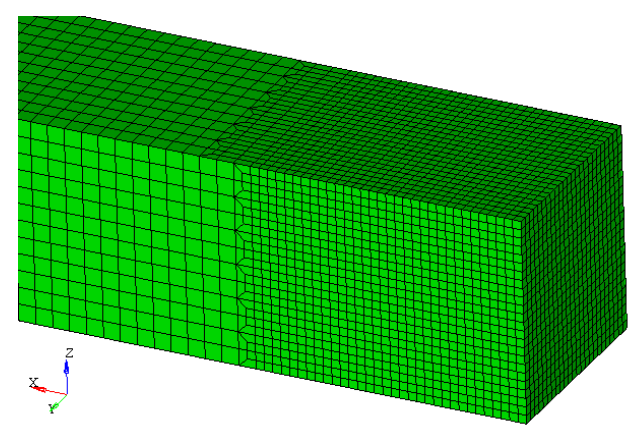

Figure 35. Local mesh refinement in beam near impact region. Average mesh size was reduced by half.

It was verified that mesh refinement allowed to generation of high stress concentrations in the area of specimen in contact with sharp edge of indenter. For maximum shear stress failure criterion this caused an indentation in mesh followed by failure of beam, in a very similar manner from what is observed in experimental tests as shown in Figure 36, however, failure occurred at instant $0.0036 \mathrm{~s}$, earlier than failure using a coarse mesh.

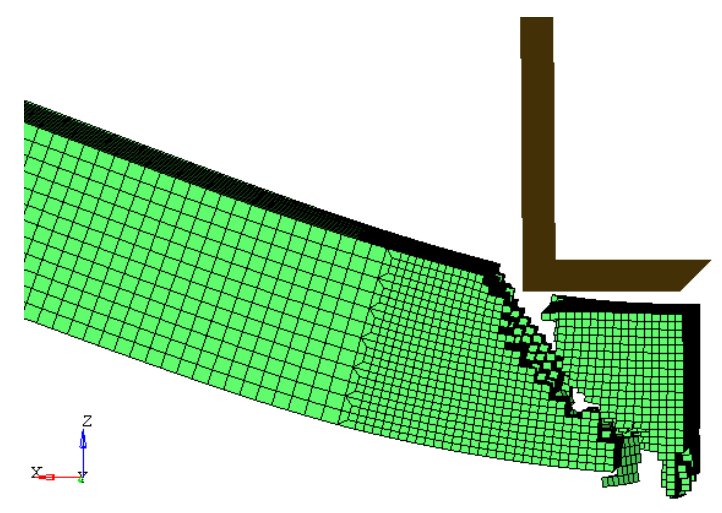

Figure 36. Failure generated by maximum shear stress criterion. 
For refined mesh, local concentration of shear strain and equivalent plastic strain developed in contact region of specimen with sharp edge of indenter, but failure criteria based on these quantities did not generate failure of beam. Regarding Johnson-Cook failure criterion, a refined mesh for specimen increased a little the maximum accumulated damage in simulation, so that a maximum damage of 0.849 was reached, with a damage distribution very similar to Figure 34. For maximum equivalent stress failure criterion, a refined mesh for specimen generated a local concentration of stress in region of contact between beam and sharp edge of indenter which generated an indentation and after a failure, at instant $0.004 \mathrm{~s}$, which propagated in a plane perpendicular to beam axis, as shown in Figure 37.

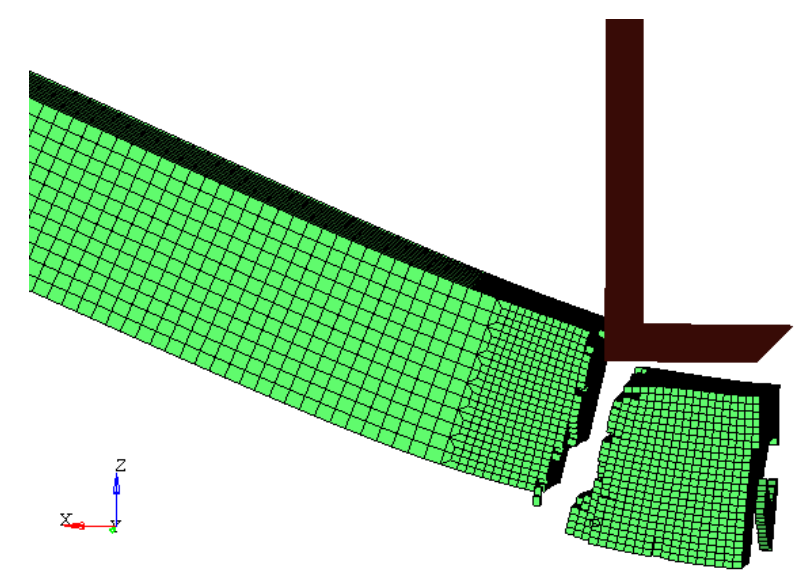

Figure 37. Failure generated by maximum equivalent stress criterion.

\section{CONCLUSIONS}

Different failure criteria available in finite element solver LS-Dyna were tested in this work for simulation of failure in steel beams under impact. A methodology for material and failure criteria characterization as well as improvement of data acquisition system for experimental tests were developed, and can be applied in future studies. Failure of beams is a complex phenomenon, so that for future work it is suggested the implementation of failure subroutines that account for more variables in the modeling of failure phenomenon.

\section{Acknowledgements}

The authors would like to thank all colleagues from Impact Laboratory of University of São Paulo for supporting this work.

\section{REFERENCES}

[1] Chen, F. L., Yu, T. X., "A further study of plastic shear failure of impulsively loaded clamped beams", International Journal of Impact Engineering 24, 613 - 629, 2000.

[2] Johnson, G. R., Cook, W. H., “A constitutive model and data for metals subjected to large 
strains, high strain rates and high temperatures", Proceedings of the Seventh International Symposium on Ballistics. The Hague, p. 541, 1983.

[3] Jones, N., "Plastic failure of ductile beams loaded dynamically", Trans. ASME, J. Engng Ind. 98B, 131-136, 1976.

[4] Jones, N., Alves, M., "Post-severance analysis of impulsively loaded beams", International Journal of Solids and Structures 41, 6441 - 6463, 2004.

[5] Jones, N., Li, Q. M., "Shear and adiabatic shear failures in an impulsively loaded fully clamped beam”, International Journal of Impact Engineering 22, 589-607, 1999.

[6] Li, Q. M., Ye, Z. Q., Ma, G. W., Jones, N., Zhou, H. Y., "The influence of elastic shear deformation on the transverse shear failure of a fully clamped beam subjected to idealized blast loading", International Journal of Mechanical Sciences 51, 413-423, 2009.

[7] Liu J, Jones N. "Experimental investigation of clamped beam struck transversely by a mass", International Journal of Impact Engineering 4, 303-35, 1987.

[8] Menkes SB, Opat HJ. "Broken beams”, Exp Mech 13, 480-6, 1973.

[9] Shen, W. Q., Jones, N., "A failure criterion for beams under impulsive loading", International Journal of Impact Engineering 12, 101-121, 1992. 